\title{
Magnetic Properties and Oxygen Defects of Dilute Metal Doped Tin Oxide Based Semiconductor
}

\author{
Kiyoshi Nomura
}

Photocatalytic International Research Center, Tokyo University of Science, 2641 Yamazaki, Noda-city, Chiba, 278-8501, Japan

Author's e-mail address: dqf10204@nifty.com

RECEIVED: November 12, 2015 * REVISED: December 27, 2015 * ACCEPTED: December 28, 2015

THIS PAPER IS DEDICATED TO DR. SVETOZAR MUSiĆ ON THE OCCASION OF HIS 70Th BIRTHDAY

Abstract: Chemical and magnetic states of iron doped tin oxide $\left(\mathrm{SnO}_{2}\right)$ as a diluted magnetic semiconductor (DMS) at room temperature have been investigated using ${ }^{57} \mathrm{Fe}$ Mössbauer spectrometry, XRD and magnetometery. The influence of the doping conditions of $\mathrm{SnO}_{2}$ with iron on the generation of oxygen defects was reviewed and discussed on the basis of ab initio calculations.

The magnetic properties depended on preparation conditions, such as thermal decomposition and sol-gel processing as well as ${ }^{57} \mathrm{Fe}$ and super-dilute ${ }^{57} \mathrm{Mn}$ implantation. It was shown that $\mathrm{Sb}$ codoping in $\mathrm{Fe}$ doped $\mathrm{SnO}_{2}$ increases the saturation magnetization. Doping of $\mathrm{Fe}(\mathrm{Sb})-\mathrm{SnO} \mathrm{S}_{2}$ with nonmagnetic $\mathrm{Zn}$ ions up to $7 \%$ also increases the magnetization although there is no precipitation of crystalline magnetic phases. The codoping of two transition metal ions ( $\mathrm{Fe}-\mathrm{Co}, \mathrm{Fe}-\mathrm{Mn}$, Fe-Ni and Fe- $\mathrm{V}$ ) in $\mathrm{SnO}_{2}$ matrix enhanced the magnetization as compared with that of single metal ion doped samples. It is suggested from different valence states of doped metal ions that double exchange interactions occur through or near the oxygen vacancies in $\mathrm{SnO}_{2}$.

The $\mathrm{SnO}_{2}$ doped with dilute ${ }^{57} \mathrm{Fe}$ may show the intrinsic and/or extrinsic DMS properties. Oxygen vacancies play an important role in the intrinsic DMS. The intrinsic nature of DMS is supported by both, experimental results and ab initio calculations. The long range interactions between diluted magnetic ions are considered to occur through electrons produced by oxygen vacancies or electrons induced by $\mathrm{Sb}^{5+}$ doping.

Keywords: diluted magnetic semiconductor (DMS), Mössbauer spectrometry, ${ }^{57} \mathrm{Fe}$ doped $\mathrm{SnO}_{2}$ semiconductor, $\mathrm{SnO}_{2}$ co-doped with two metals, $a b$ initio calculation.

\section{INTRODUCTION}

0 XIDE diluted magnetic semiconductors (DMSs), which possess good semiconducting and magnetic properties at room temperature (RT), are promising materials for spintronic devices. Magnetic alloy semiconductors (II$\mathrm{VI}, \mathrm{III}-\mathrm{V}$ ) such as Mn doped ZnTe, GaAs and InAs, which show ferromagnetism at low temperatures, have already been utilized as spintronic devices. ${ }^{[1]}$ The first oxide DMS system was reported by Matsumoto et al. (2001). The authors showed that $\mathrm{Co}$ doped $\mathrm{TiO}_{2}$ films prepared by laser ablation show ferromagnetism at $R T$. $^{[2]} \mathrm{T}$. Dietel et al. ${ }^{[3 a]}$ And Pearton et al. ${ }^{[3 \mathrm{~b}]}$ showed the relationship between band gap and Curie temperature of semiconductors. ${ }^{[3]}$ In order to realize RT-DMS, the semiconductor with large band gap is profitable as candidate material. ${ }^{[3]}$ Ogale et al. reported that transparent Co-doped $\mathrm{SnO}_{2}$ shows the high temperature ferromagnetism with a giant magnetic moment. ${ }^{[4]}$ This seems to be due to precipitated magnetic compounds. $\mathrm{SnO}_{2}$ film with band gap of $3.6 \mathrm{eV}$ is transparent and electrically conductive. $\mathrm{SnO}_{2}$ doped with metal ions has been used for a gas sensor working at temperatures of several hundred degrees Celsius. ${ }^{[5]}$

There remain the questions why the magnetic moment in oxide semiconductors increases by doping them with small amounts of magnetic ions, and why the DMSs show high Curie temperature. The study of the magnetism in diluted magnetic oxides became an interesting issue over the last decade. ${ }^{[6]}$ Coey et al. reported the magnetic polaron models and the charge transfer band models with impurity band as dilute magnetic mechanism. ${ }^{[7]}$ Which dilute magnetic oxide semiconductor is fact or fiction is discussed. ${ }^{[8]}$ It is necessary to reveal the chemical and magnetic states of doped metal ions in semiconductors and whether the doped metal ions exist as uniformly dispersed metal ions, clusters and/or precipitated compounds. 
${ }^{57} \mathrm{Fe}$ Mössbauer spectrometry provides the information of electronic and magnetic states of iron nanomaterials. Conversion electron Mössbauer spectrometry and X-ray Mössbauer spectrometry (CEMS and XMS) can be used for characterization of iron included in solid surface and thin layers. ${ }^{[9]}$ The vibration density states (VDOS) of oxides containing Mössbauer nuclei can be characterized by another Mössbauer technique, the nuclear resonance inelastic scattering (NIS) using synchrotron radiation. ${ }^{[10]}$ Thus, the valence states, magnetic states, and local VDOS of Fe doped oxide semiconductors can be clarified by using Mössbauer techniques of ca. $1 \%{ }^{57} \mathrm{Fe}$ probes.

Various transparent DMS films have been characterized by ${ }^{57} \mathrm{Fe}$ CEMS. For example, transparent $6 \%$ ${ }^{57} \mathrm{Fe}$ doped $\mathrm{TiO}_{2}$ film, prepared by laser ablation in vacuum of $1.33 \times 10^{-6} \mathrm{~Pa}$, shows Kerr effect (optical ferromagnetism) at RT. It was clarified by ${ }^{57} \mathrm{Fe}$ CEMS that the magnetic origin is mainly due to metallic Fe clusters. ${ }^{[11]}$

In this review article, ${ }^{57} \mathrm{Fe}$ Mössbauer analytical results and magnetic properties of $\mathrm{SnO}_{2}$ based materials doped with diluted $\mathrm{Fe}$ ions are introduced together with theoretical results obtained by $a b$ initio calculation for configurations of substituted $\mathrm{Fe}$ and oxygen defects of $\mathrm{Fe}$ doped $\mathrm{SnO}_{2} \cdot{ }^{[12]}$
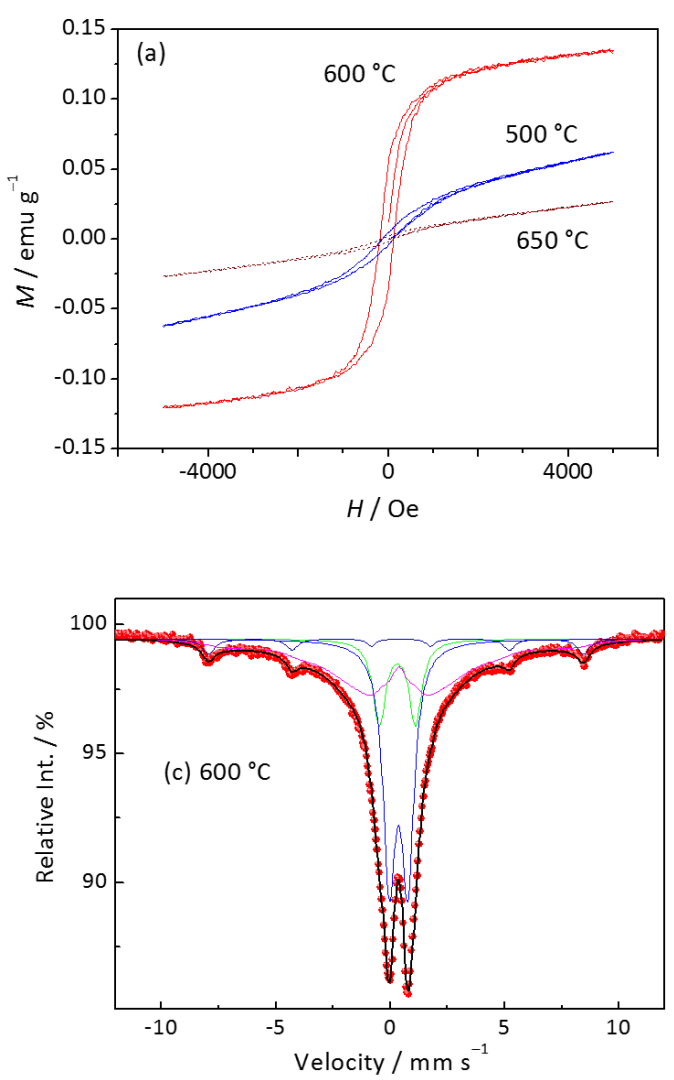

\section{MAGNETIC PROPERTIES OF Fe DOPED Sn OXIDE POWDER}

\author{
Fe Doped $\mathrm{SnO}_{2}{ }^{[13]}$
}

10 at $\% \mathrm{Fe}$ doped $\mathrm{SnO}_{2}$ powder was prepared by a sol-gel method and the thermal decomposition. The relationship between magnetization curves and annealing conditions is shown in Figure 1 (a). The ferromagnetic hysteresis including a paramagnetic component is observed.

The magnetic hysteresis depends on annealing temperatures. 10 at \% Fe doped $\mathrm{SnO}_{2}$ annealed at $600{ }^{\circ} \mathrm{C}$ shows the highest saturation magnetization. The magnetic relaxation peaks are observed in addition to paramagnetic doublets and a minor sextet of $\mathrm{Fe}_{2} \mathrm{O}_{3}$ in the Mössbauer spectrum. The sample annealed at $500{ }^{\circ} \mathrm{C}$ shows only two doublets of $\mathrm{Fe}^{3+}$ although the saturation magnetization is larger than that of the sample annealed at $650{ }^{\circ} \mathrm{C}$, which contains the weak magnetic component of $\mathrm{Fe}_{2} \mathrm{O}_{3}$. The doped Fe species are embedded in so large grains of matrix $\mathrm{SnO}_{2}$ that cannot show the superparamagnetism. However, there remains the question why the ferromagnetic behavior is obtained.
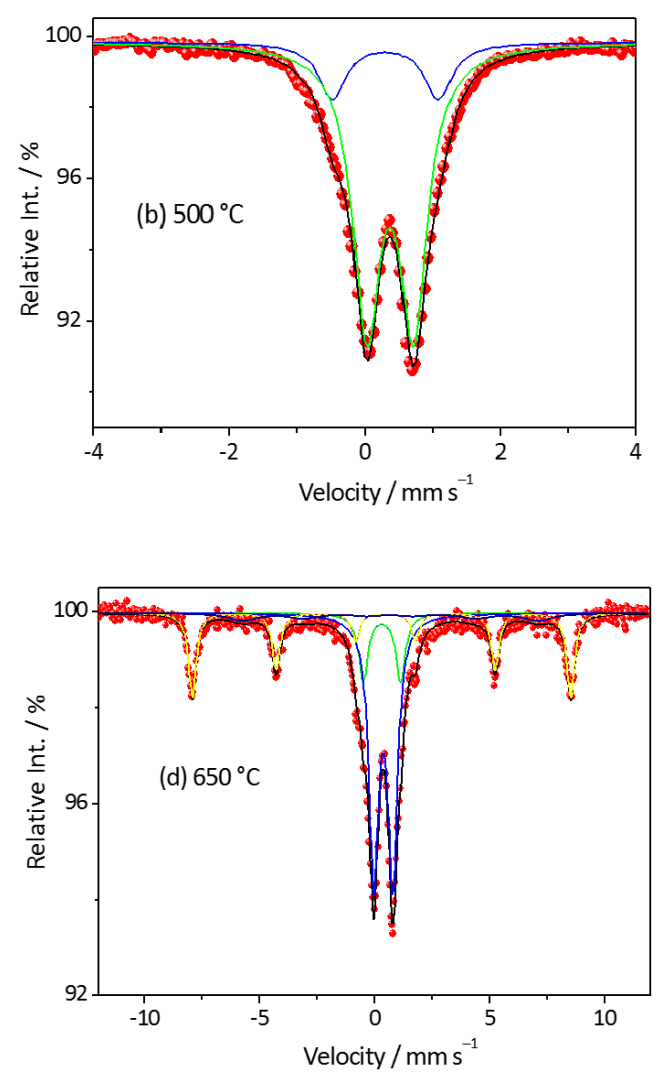

Figure 1. (a) Magnetic hysteresis of 10 at \% Fe doped $\mathrm{SnO}_{2}$ annealed at various temperatures for 2 hours; (b) Mössbauer spectra of the sample annealed at $500{ }^{\circ} \mathrm{C}$, (c) the sample annealed at $600{ }^{\circ} \mathrm{C}$; and (d) the sample annealed at $650{ }^{\circ} \mathrm{C}$. [13] 


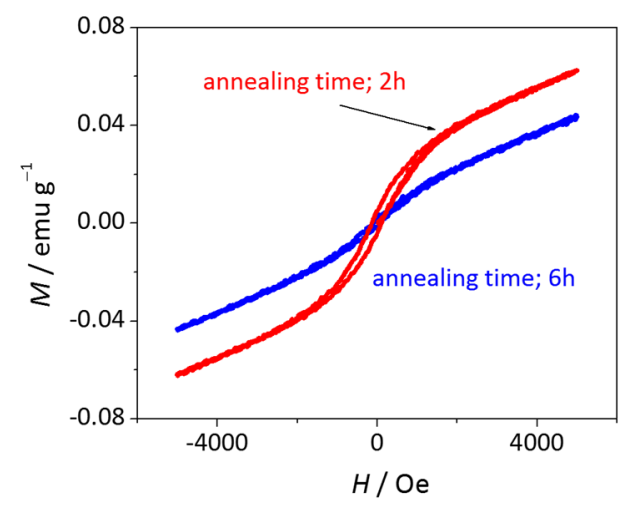

Figure 2. Effect of annealing at $500{ }^{\circ} \mathrm{C}$ on magnetization of 10 at $\%$ Fe doped $\mathrm{SnO}_{2} \cdot{ }^{[13]}$.

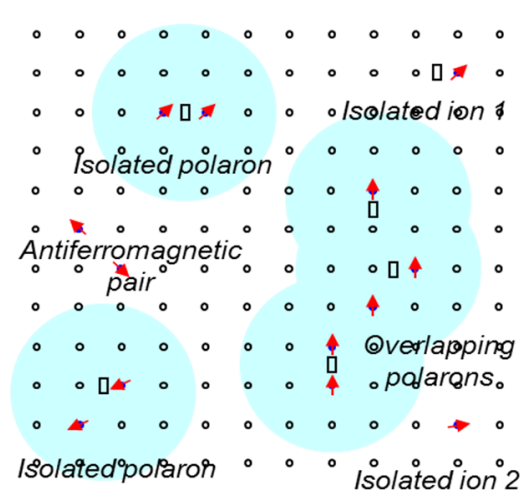

Figure 3. Diagram on the formation of polaron. Oxygen atoms are not displayed. [: oxygen deficiency. ${ }^{[7]}$

As shown in Figure 2, the saturation magnetization $\left(M_{s}\right)$ of the sample heated at $500{ }^{\circ} \mathrm{C}$ for 2 hours decreases by annealing at $500{ }^{\circ} \mathrm{C}$ further for 4 hours. The oxygen defects are considered to be repaired by annealing for long time. Therefore, the magnetization is related to oxygen defects induced at the initial annealing. Two doublets observed in Fig. 1 (b) are assigned to $\mathrm{Fe}^{3+}$ (isomer shift (IS) $=0.34 \mathrm{~mm} \mathrm{~s}^{-1}$, quadrupole splitting (QS) $=0.80 \mathrm{~mm} \mathrm{~s}^{-1}$ ) and $\mathrm{Fe}^{3+}\left(\mathrm{IS}=0.28 \mathrm{~mm} \mathrm{~s}^{-1}, \mathrm{QS}=1.60 \mathrm{~mm} \mathrm{~s}^{-1}\right)$. This suggests that high spin $\mathrm{Fe}^{3+}$ ions interact as a long range ordering through electron spin localized at oxygen deficiency under the magnetic fields, that is defect induced ferromagnetism due to overlapped polarons as shown in Figure 3 .

\section{$\mathrm{Sb}$ and Fe Codoped $\mathrm{SnO}_{2}{ }^{[14]}$}

$\mathrm{Sn}^{4+} \mathrm{O}_{2}$ doped with $\mathrm{Sb}^{5+}$ is n-type semiconductor, whereas $\mathrm{SnO}_{2}$ doped with $\mathrm{Fe}^{3+}$ is $\mathrm{p}$-type semiconductor. The ionic radii are $0.069 \mathrm{~nm}$ for $\mathrm{Sn}^{4+}, 0.064 \mathrm{~nm}$ for $\mathrm{Fe}^{3+}$, and $0.060 \mathrm{~nm}$ for $\mathrm{Sb}^{5+}$, respectively. Doping $\mathrm{Sb}^{5+}$ into $\mathrm{SnO}_{2}$ increases the electric conductivity and the solubility of $\mathrm{Fe}^{3+}$ doped. The saturation magnetization of $\mathrm{Sn}_{0.8-y} \mathrm{Fe}_{0.2} \mathrm{Sb}_{y} \mathrm{O}_{2}$ increases with

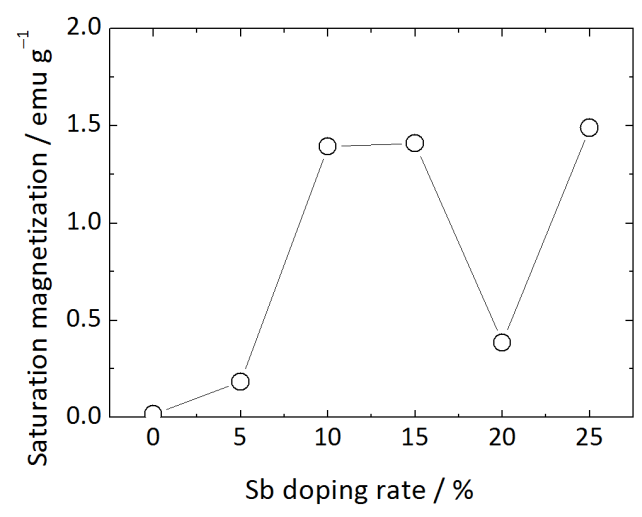

Figure 4. Dependence of saturation magnetization on doping rate of $\mathrm{Sb}$ in 20 at \% Fe doped $\mathrm{SnO}_{2} \cdot{ }^{[14]}$

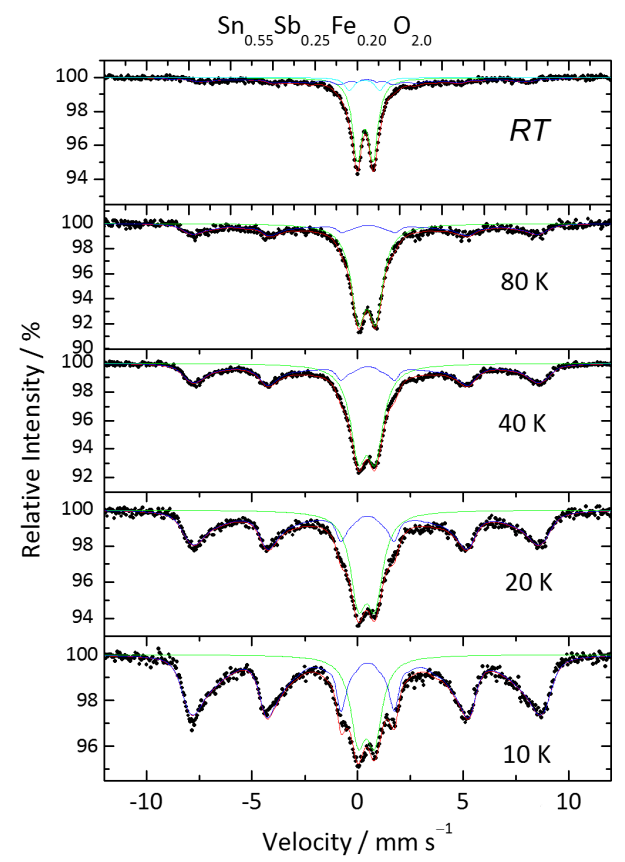

Figure 5. Mössbauer spectra of $\mathrm{Sn}_{0.55} \mathrm{Fe}_{0.2} \mathrm{Sb}_{0.25} \mathrm{O}_{2}$, measured at $10 \mathrm{~K}, 20 \mathrm{~K}, 40 \mathrm{~K}$, and $R T^{[14]}$

the increase of $\mathrm{Sb}$ as shown in Figure 4. ${ }^{[14]}$ However, the magnetization decreases by compensating the induced carrier density by holes formed when the doping rate of $\mathrm{Sb}$ becomes almost the same as that of Fe.

Mössbauer spectra of $\mathrm{Sn}_{0.8-y} \mathrm{Fe}_{0.2} \mathrm{Sb}_{y} \mathrm{O}_{2}(y=0.25)$ show major doublets and a minor magnetic sextet at RT. The magnetization is relatively large and the coercivity is small like soft magnetic behavior. When Mössbauer spectra are measured at low temperatures, the area intensity of doublets is relatively transferred into that of a broad sextet with the decrease of the measuring temperature as shown in Figure 5. The hyperfine fields are not so dependent on the measuring temperature. It is considered that the 


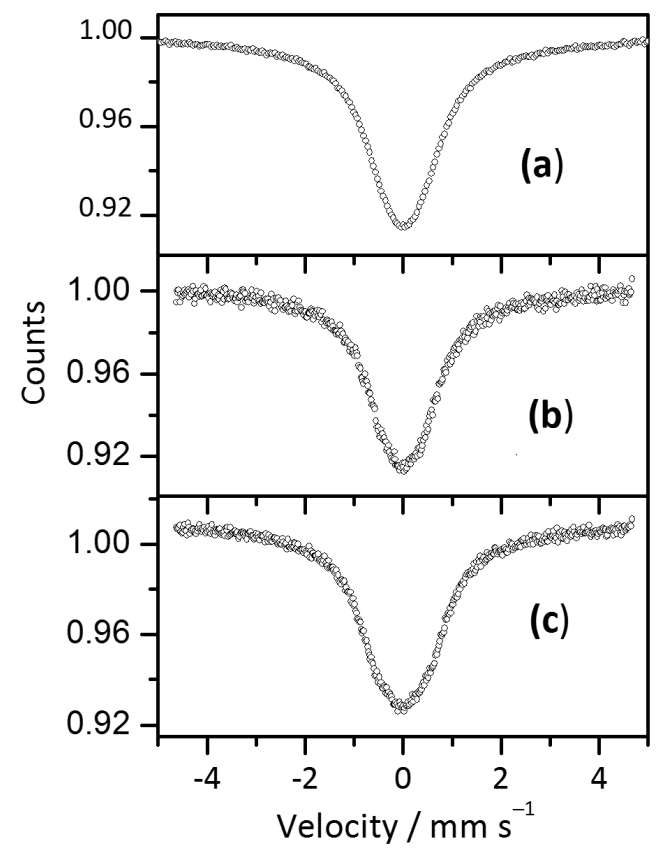

Figure 6. ${ }^{119} \mathrm{Sn}$ Mössbauer spectra of $\mathrm{Fe}_{x} \mathrm{Sb}_{y} \mathrm{Sn}_{1-x-y} \mathrm{O}_{2-\delta}$ : (a) no applied field; (b) $0.3 \mathrm{~T}$ applied field; (c) $0.55 \mathrm{~T}$ applied field. ${ }^{[15]}$

doublet peaks obtained at RT are not due to fine particles of iron oxides, but due to the small domain size, that is the spin-spin interaction. It is to note that a ferromagnetic behavior including a paramagnetic component is observed in the magnetic hysteresis curves although almost all samples

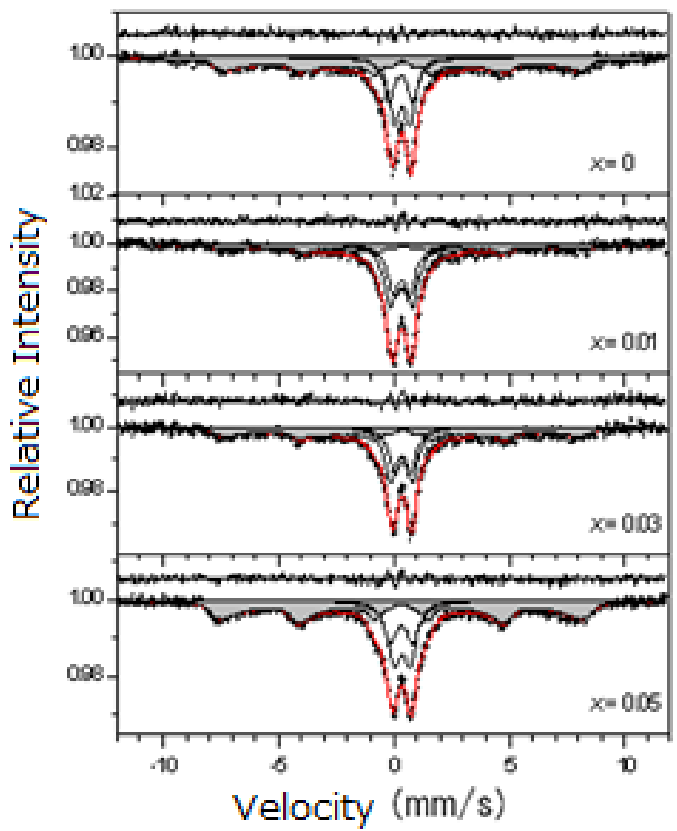

show the doublets of paramagnetic $\mathrm{Fe}^{3+}$. The abnormal phenomena are considered due to the exchange coupling between local electron spin of $\mathrm{Fe}^{3+}$ through the carrier electrons doped. The magnetic moment of $\mathrm{Fe}^{3+}$ induces the polarization of carrier electrons, which interact with the next neighbor $\mathrm{Fe}^{3+}$. Thus, the possible mechanism is considered to be connected with the exchange interactions between iron ions and magnetic defects being mediated by impurity induced free charge carriers.

As compared with single $\mathrm{Fe}$ ion doped $\mathrm{SnO}_{2}, \mathrm{Sb}$ and Fe codoping into $\mathrm{SnO}_{2}$ results in enhancement of saturation magnetization without the precipitation of impurities. This suggests that the origin of ferromagnetism is mainly due to the increase of electron carrier density by doping $\mathrm{Sb}^{5+}$.

\section{${ }^{119}$ Sn Mössbauer Spectrum of Fe Doped $\mathrm{SnO}_{2}{ }^{[15]}$}

${ }^{119} \mathrm{~S} n$ is not a magnetic atom itself. However, the transition by gamma ray absorption occurs between the exited state of nuclear $\operatorname{spin} I=3 / 2$ and the ground state of $I=1 / 2$. In ${ }^{119} \mathrm{Sn}$ Mössbauer spectra measured under the applied magnetic fields, the magnetic sextet is expected to appear like ${ }^{57} \mathrm{Fe}$ Mössbauer spectrum. When ${ }^{119} \mathrm{Sn}$ Mössbauer spectra of $\mathrm{Sn}_{0.8-y} \mathrm{Fe}_{0.2} \mathrm{Sb}_{y} \mathrm{O}_{2}$ were measured under magnetic fields of $0.3 \mathrm{~T}$ and $0.55 \mathrm{~T}$, the peak with broaden width was observed in ${ }^{119} \mathrm{Sn}$ Mössbauer spectra as shown in Figure 6. Thus, it is found that even ${ }^{119} \mathrm{Sn}$ nucleus in the bulk area is also sensitive to applied magnetic fields. ${ }^{[15]}{ }^{119} \mathrm{Sn}$ can be used as one of magnetic probes for dilute magnetic materials.

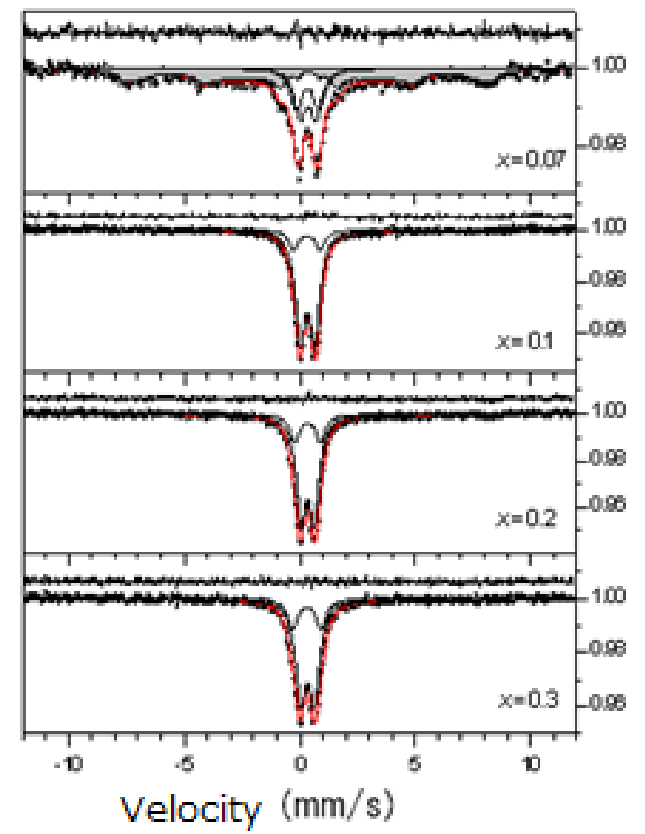

Figure 7. Mössbauer spectra of $\mathrm{Zn}_{x} \mathrm{Fe}_{0.2} \mathrm{Sb}_{0.1} \mathrm{Sn}_{1-(x+0.3)} \mathrm{O}_{2}$. 


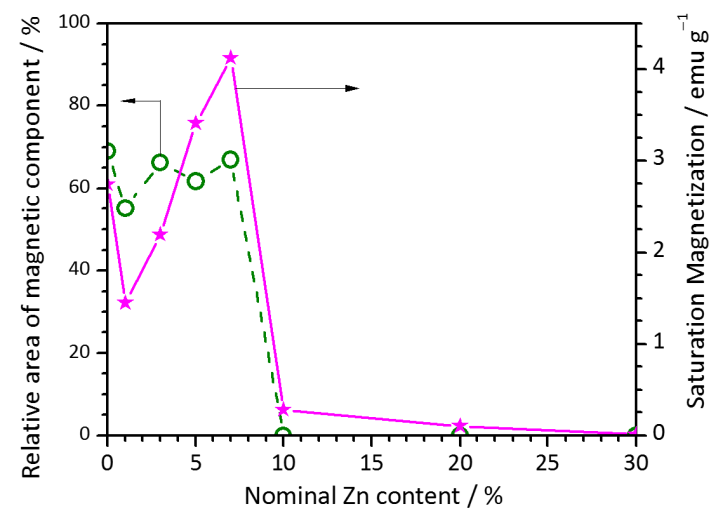

Figure 8. Relative area intensity of magnetic components in Mössbauer spectra and saturation magnetization of $\mathrm{Zn}_{x} \mathrm{Fe}_{0.2} \mathrm{Sb}_{0.1} \mathrm{Sn}_{1-(x+0.3)} \mathrm{O}_{2}$.

\section{Nonmagnetic Zn Doped$$
\mathrm{Fe}_{x} \mathrm{Sb}_{y} \mathrm{Sn}_{1-x-y} \mathrm{O}_{2-\delta}{ }^{[16]}
$$

XRD peaks of $\mathrm{Zn}$ doped $\mathrm{Fe}_{x} \mathrm{Sb}_{y} \mathrm{Sn}_{1-x-y} \mathrm{O}_{2-\delta}$ show only the rutile structure of $\mathrm{SnO}_{2}$ even if doped with $\mathrm{Zn}$ up to $7 \%$, whereas the spinel, $\mathrm{Zn}_{2} \mathrm{SnO}_{4}$, is additionally observed for more than $10 \% \mathrm{Zn}$ doped samples. XRD peaks of $\mathrm{Zn}_{2} \mathrm{SnO}_{4}$ are almost similar to those of spinel $\mathrm{ZnFe}_{2} \mathrm{O}_{4}$. The Mössbauer spectra are composed of two paramagnetic doublets and magnetic relaxation peaks as shown in Figure 7. A doublet with small QS was assigned to $\mathrm{Fe}^{3+}$ coordinated with six oxygen atoms and another doublet with large QS was assigned to $\mathrm{Fe}^{3+}$ closed to oxygen vacancy. However, both doublets are due to $\mathrm{Fe}^{3+}$, which are located close to oxygen vacancies in different configurations as described later in section Magnetic moments and oxygen vacancies of $\mathrm{Fe}$ doped $\mathrm{SnO}_{2}$ by ab initio calculation. The area intensity of magnetic relaxation component and the saturation magnetization are plotted for doping rate of $\mathrm{Zn}$, respectively, as shown in Figure 8. It is found that the saturation magnetization is correlated with magnetic relaxation component of $\mathrm{Fe}^{3+}$. When more than $10 \% \mathrm{Zn}$ is doped, the magnetic relaxation component disappears in the Mössbauer spectra, but the weak magnetization is remaining. It is considered due to magnetic defects produced at the interface between the precipitated impurity and $\mathrm{SnO}_{2}$ matrix.

\section{$\mathrm{SnO}_{2}$ Codoped With Two Transition Metal lons}

In the case of single metal ion doped $\mathrm{SnO}_{2}$, it is known that the saturation magnetization increases with Fe concentration, but decreases with Co concentration. The codoping effect of $\mathrm{Fe}$ and $\mathrm{Co}$ doped $\mathrm{SnO}_{2}$ were studied. ${ }^{[17,18]}$ The samples were prepared by a sol-gel method and a thermal decomposition at $550{ }^{\circ} \mathrm{C}$. The crystallite size is about 20$40 \mathrm{~nm}$ in diameter. As shown in Figure 9, 1 \% Fe and $0.5 \%$

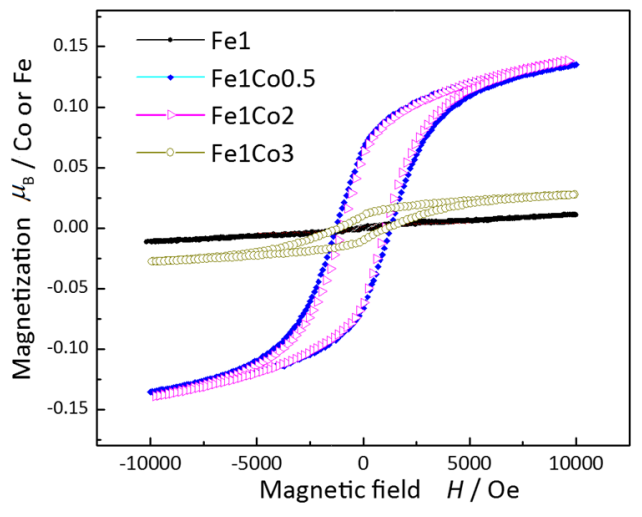

Figure 9. Magnetic hysteresis of $1 \% \mathrm{Fe}$ and $y \%$ Co codoped $\mathrm{SnO}_{2} \cdot[17]$

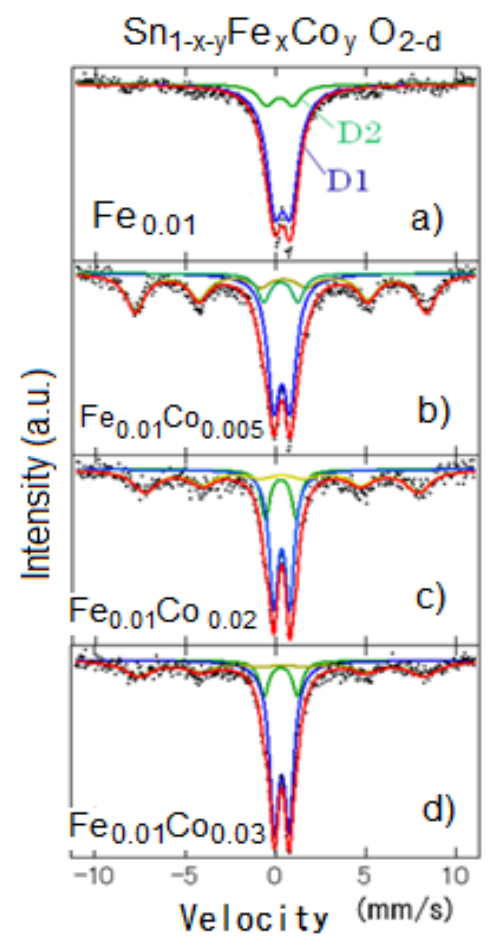

Figure 10. ${ }^{57} \mathrm{Fe}$ Mössbauer spectra of $\mathrm{SnO}_{2}$ doped with $1 \%$ Fe and (a) $0 \%$; (b) $0.5 \%$; (c) $2 \%$; and (d) $3 \%$ Co. ${ }^{[17]}$

Co codoped $\mathrm{SnO}_{2}$ enhances the saturation magnetization $\left(M_{s}\right)$. When more than $3 \% \mathrm{Co}$ are doped into Fe doped $\mathrm{SnO}_{2}$, the magnetization decreases. There is a possibility that ferrite is precipitated with increase of Co content, but the broad magnetic components as shown in Fig. 10 are absolutely different from that of $\mathrm{CoFe}_{2} \mathrm{O}_{4}$. It is hard to consider the precipitated ferrite as the origin of ferromagnetism. It is not sure whether a double exchange interaction of Fe and Co through Sn and O occur or not, but it was confirmed from Co $L$ absorption edge in XAFS that $1 \%$ Co ions have the mixed valence states of $2+$ and $3+$. It 
is considered that the local electrons existing in oxygen deficiency and isolated Sn atoms are intermediates between ferromagnetic interactions.

The magnetization properties of $\mathrm{Mn}$ and Fe codoped $\mathrm{SnO}_{2}$, and Fe and $\mathrm{Ni}$ codoped $\mathrm{SnO}_{2}$ are also studied. ${ }^{[19,20]}$

Dilute Fe-Mn codoped $\mathrm{SnO}_{2}$ is synthesized by a solgel method. The Fe-Mn codoping enhances the magnetization in comparison with the case of single metal ion doping. The $M_{\mathrm{s}}$ values are correlated with the crystallite sizes. Mössbauer spectrometry revealed the magnetic sextet and relaxation peaks, which suggest that Fe ions doped contribute to the magnetic ordering and super-paramagnetic properties. X-ray absorption spectroscopy revealed that $\mathrm{Mn}^{3+}$ and $\mathrm{Mn}^{2+}$ mixed states are dominant in Fe-Mn codoped $\mathrm{SnO}_{2} \cdot{ }^{[19]}$

In the case of $\mathrm{Fe}-\mathrm{Ni}$ codoped $\mathrm{SnO}_{2}$, the following possibilities for the origins of RT ferromagnetism are considered. The formation of $\mathrm{Fe}$ and $\mathrm{Ni}$ complex oxides might become one of the candidates for ferromagnetic ordering, since $\mathrm{Ni}$-based spinel-type ferrite is well known as a ferromagnetic material. However, the observed doping dependencies in $M_{\mathrm{s}}$ of Fe-Ni codoped $\mathrm{SnO}_{2}$ cannot be explained by the simple formation of secondary phases. It is therefore deduced that the Fe-Ni codoping enhances the $M_{s}$ not by the segregation of secondary phases but by the exchange interaction. ${ }^{[20]}$

In the case of $\mathrm{Fe}-\mathrm{V}$ codoped $\mathrm{SnO}_{2}, \mathrm{Fe}-\mathrm{V}$ codoping also enhanced the $M_{s}$, which showed the maximum $M_{\mathrm{s}}$ at $1 \% \mathrm{~V}$ and $1 \%$ Fe codoping. With further increase of Fe-V codoped into $\mathrm{SnO}_{2}$ host, the $M_{\mathrm{s}}$ decreased. Chemical states of vanadium ions were deduced as $\mathrm{V}^{5+}$ states by XAS. Mössbauer spectrometry revealed that the intensity of sextet components is related to the $M_{s}$, which indicates that small amounts of Fe-V codoped are effective to enhance $M_{s}{ }^{[21]}$ It is to note that the sextet component is like hematite, which shows weak ferromagnetism at $R T$ although the XRD peaks of hematite are not be detected.

As compared with single metal doped $\mathrm{SnO}_{2}$, the ferromagnetic exchange interaction is enhanced by codoping two transition metal ions. A codoping technique that employs different $d$ electron numbers becomes essential for the stabilization of ferromagnetism with the control of both saturation magnetization $\left(M_{s}\right)$ and the coercive field $\left(H_{\mathrm{c}}\right)$ at $R T$. $^{[20]}$

\section{Fe ION IMPLANTED $\mathrm{SnO}_{2}$ FILM $^{[22]}$}

${ }^{57} \mathrm{Fe}$ ions are implanted into $\mathrm{SnO}_{2}$ film ( $200 \mathrm{~nm}$ in thickness) on fused quartz glass, heated at RT, $300{ }^{\circ} \mathrm{C}$, and $500{ }^{\circ} \mathrm{C}$, respectively. The ion implantation energy is $100 \mathrm{keV}$, and the flux is $1 \times 10^{17} \mathrm{Fe}$ ions $/ \mathrm{cm}^{2}$. According to Monte Carlo calculation (using the Transport of lons in Matter: TRIM), Fe concentration reaches the maximum $10 \%$ in the depth of
$40 \mathrm{~nm}$ of $\mathrm{SnO}_{2}$ film. The magnetic hysteresis was a little observed at substrate temperature of $300{ }^{\circ} \mathrm{C}$, but disappeared after annealing.

\section{${ }^{57}$ Fe Ion Implantation at $R T^{[23]}$}

$\mathrm{SnO}_{2}$ film implanted with ${ }^{57} \mathrm{Fe}$ at $\mathrm{RT}$ did not show Kerr effect at all. ${ }^{119} \mathrm{Sn}$ CEM spectra of $\mathrm{SnO}_{2}$ film implanted with $1 \times 10^{17}$ ions $/ \mathrm{cm}^{257} \mathrm{Fe}$ are composed of two doublets of $\mathrm{Sn}^{4+}$ $(80 \%)$ and $\mathrm{Sn}^{2+}(20 \%)$. By ${ }^{57} \mathrm{Fe}$ ion implantation, $\mathrm{Sn}^{4+}$ in oxide film is partially reduced into $\mathrm{Sn}^{2+}$, whereas implanted ${ }^{57} \mathrm{Fe}^{2+}$ is oxidized into $\mathrm{Fe}^{3+}$. With the increase of annealing temperatures, $\mathrm{Sn}^{2+}$ ions are perfectly oxidized into $\mathrm{Sn}^{4+}$ to form $\mathrm{SnO}_{2}$ rutile film.

\section{${ }^{57} \mathrm{Fe}$ Ion Implantation of $\mathrm{SnO}_{2}$ Film at Substrate Temperature of $500{ }^{\circ} \mathrm{C}^{[24]}$}

$\mathrm{SnO}_{2}$ film implanted with $5 \times 10^{16} \mathrm{Fe}$ ions $/ \mathrm{cm}^{2}$ at $500{ }^{\circ} \mathrm{C}$ shows Kerr effect as shown in Figure 11. It is transparent Fe doped $\mathrm{SnO}_{2}$ film with high electric resistance. Two magnetic sextets with broad peaks observed in Figure 12 (left side) are due to fine $\mathrm{Fe}_{3} \mathrm{O}_{4}$. The implanted ions are segregated into a cluster at the high temperature. CEM spectra of Figure 12, (a), (b) and (c) are obtained by discriminating the energy of inner conversion electrons emitted after Mössbauer effect. The low energy electrons detected reflect the deep layer because the energy of the inner conversion electrons is lost by the upper layers, whereas the high energy electrons without the energy loss reflect the top surface layer. The two doublets of $\mathrm{Fe}^{3+}$ and $\mathrm{Fe}^{2+}$ are observed in CEM spectra. It is found from their relative intensity that the $\mathrm{Fe}^{2+}$ species is located in deeper layer than in top surface layers, and that magnetite is more produced in the surface layers. Even if the sample was further heated at $400{ }^{\circ} \mathrm{C}$, the ferromagnetic behavior did not disappear. The CEM spectra of the annealed sample showed one broad sextet in addition to two doublets of $\mathrm{Fe}^{2+}$ and $\mathrm{Fe}^{3+}$. This broad sextet is due to fine maghemite $\left(\nu-\mathrm{Fe}_{2} \mathrm{O}_{3}\right)$. Peak intensity of paramagnetic $\mathrm{Fe}^{2+}$ in deep layers is not so affected by annealing in air although the peak intensity of paramagnetic $\mathrm{Fe}^{2+}$ decreases and the intensity of paramagnetic $\mathrm{Fe}^{3+}$ increases in top surface layers. The fine magnetite in surface layers is oxidized directly into a maghemite by annealing.

CEM spectra of $3 \% \mathrm{Sb}$ doped $\mathrm{SnO}_{2}$ film implanted with ${ }^{57} \mathrm{Fe}$ are the same as the CEM spectra of $1 \% \mathrm{Sb}$ doped $\mathrm{SnO}_{2}$ film implanted with ${ }^{57} \mathrm{Fe}$ although each intensity is different. It was found that $3 \% \mathrm{Sb}$ doped $\mathrm{SnO}_{2}$ film is oxidized harder than $1 \% \mathrm{Sb}$ doped $\mathrm{SnO}_{2}$ film because the relative intensity of magnetite in the former is smaller than that of the latter. The detail analysis of $3 \% \mathrm{Sb}$ doped $\mathrm{SnO}_{2}$ film implanted with ${ }^{57} \mathrm{Fe}$ and further annealed the high temperatures is referred. ${ }^{[25]}$ 

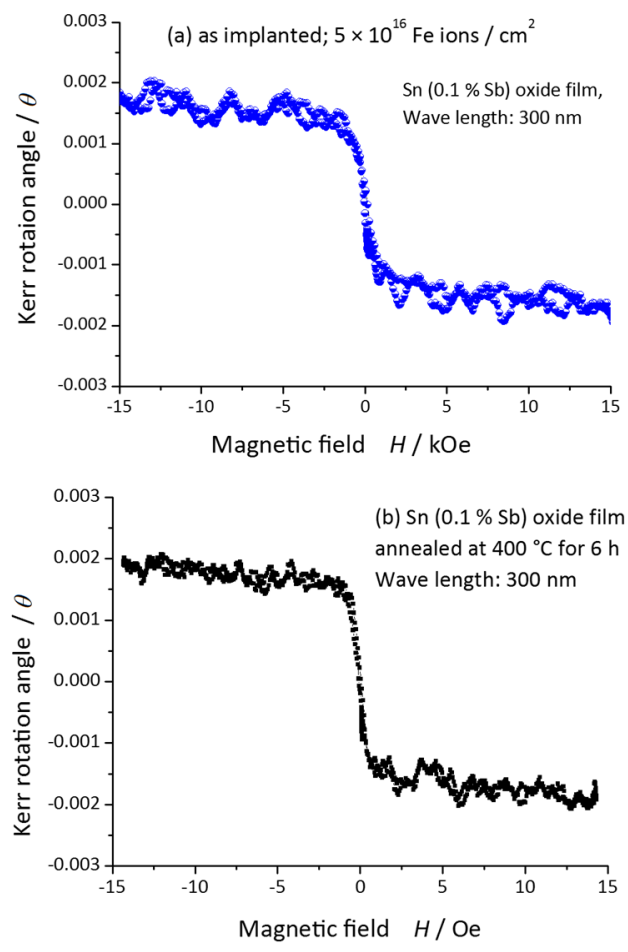

Figure 11. Magneto-optical measurement of $\mathrm{SnO}_{2}$ films (a) as implanted; (b) after annealing at $400{ }^{\circ} \mathrm{C} .{ }^{[24]}$

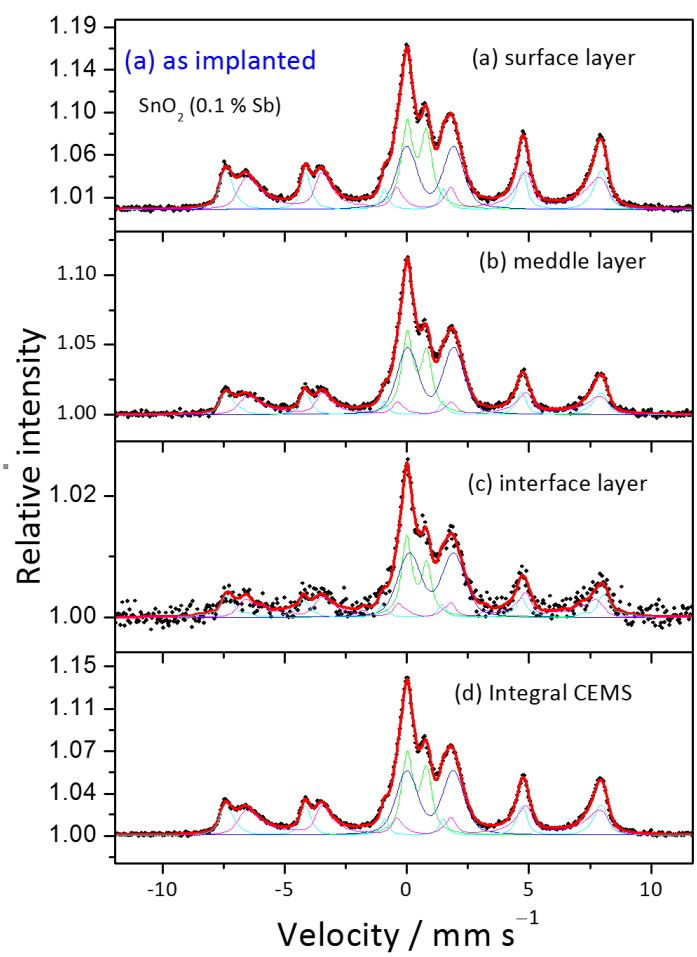

\section{Super Dilute ${ }^{57} \mathrm{Mn}$ Ion Implanted $\mathrm{SnO}_{2}$ Films $^{[26]}$}

${ }^{57} \mathrm{Fe}$ emission Mössbauer spectra of radioactive ${ }^{57} \mathrm{Mn}$ ions implanted $\mathrm{SnO}_{2}$ film are obtained on extremely dilute concentrations of $<2 \times 10^{-12}{ }^{57} \mathrm{Mn} / \mathrm{cm}^{2}$, or $<10^{-3}$ at $\%{ }^{57} \mathrm{Mn}$ as shown in Figure 13. In the $\beta$-decay of ${ }^{57} \mathrm{Mn}(T / 2=1.5 \mathrm{~min})$, the daughter ${ }^{57} \mathrm{Fe}$ is obtained by average recoil energy of $E_{\mathrm{R}}$ $=40 \mathrm{eV}$, leading to the possible formation of interstitial Fe species in the case that the bond-dissociation energy is less than the recoil energy. The emission Mössbauer spectra obtained are composed of three components: (1) a doublet marked Fe(II) with a Gaussian distribution of quadrupole splitting (QS), assigned to high-spin $\mathrm{Fe}^{2+},(2)$ magnetic hyperfine field distribution marked Fe(III), assigned to highspin $\mathrm{Fe}^{3+}$ showing slow paramagnetic relaxations, 3) a doublet component $\mathrm{Fe}_{x}$, assigned to interstitial $\mathrm{Fe}^{3+}$, not metallic Fe. From the recoil imparted on the Fe atom in the $\beta$-decay of ${ }^{57} \mathrm{Mn}$, it was tempting to assign $\mathrm{Fe}_{x}$ to interstitial Fe. ${ }^{[25]}$ However, the sharp lined doublet $\left(\mathrm{Fe}_{x}\right)$ is interpreted due to recoil produced interstitial $\mathrm{Fe}^{3+}$ from the isomer shift values. From the temperature dependence ( $143 \mathrm{~K}$ to $711 \mathrm{~K}$ ) as shown in Figure 14, the activation energy for dissociation of $\mathrm{Mn}$-VO pairs is estimated to be $0.9(1) \mathrm{eV}$. The energy is so small that the oxygen vacancy produced easily interacts

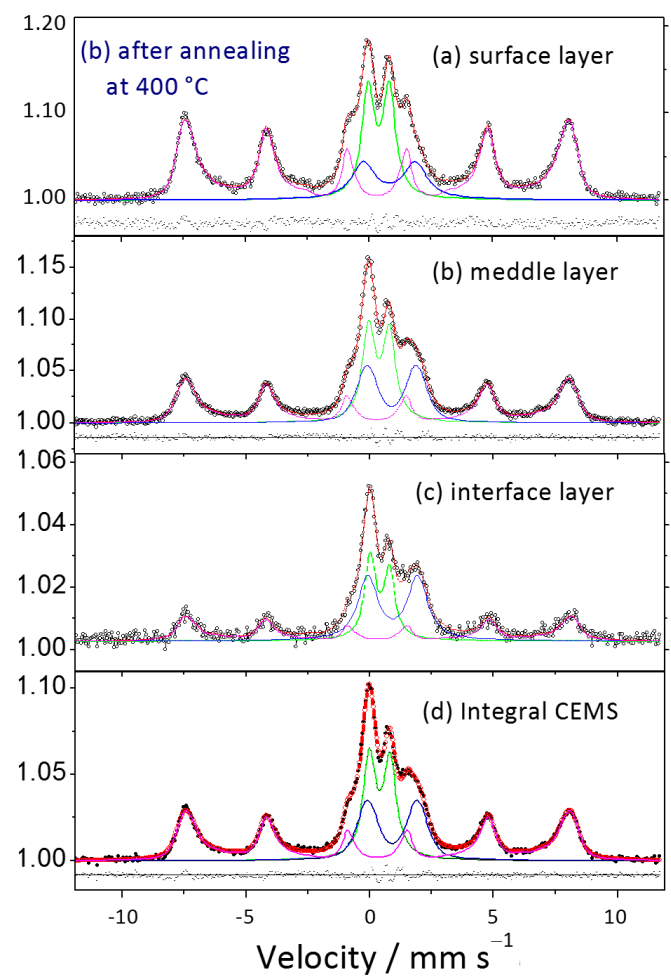

Figure 12. Depth CEM spectra of $\mathrm{SnO}_{2}$ films implanted with $5 \times 10^{16} \mathrm{Fe}$ ions $/ \mathrm{cm}^{2}$ at substrate temperature of $T_{\mathrm{s}}=500{ }^{\circ} \mathrm{C}$. [24] (a) as implanted; (b) after annealing at $400{ }^{\circ} \mathrm{C}$. From top to down: (a) surface layer; (b) middle layer; (c) under layer; and (d) integral CEMS for each spectrum. 


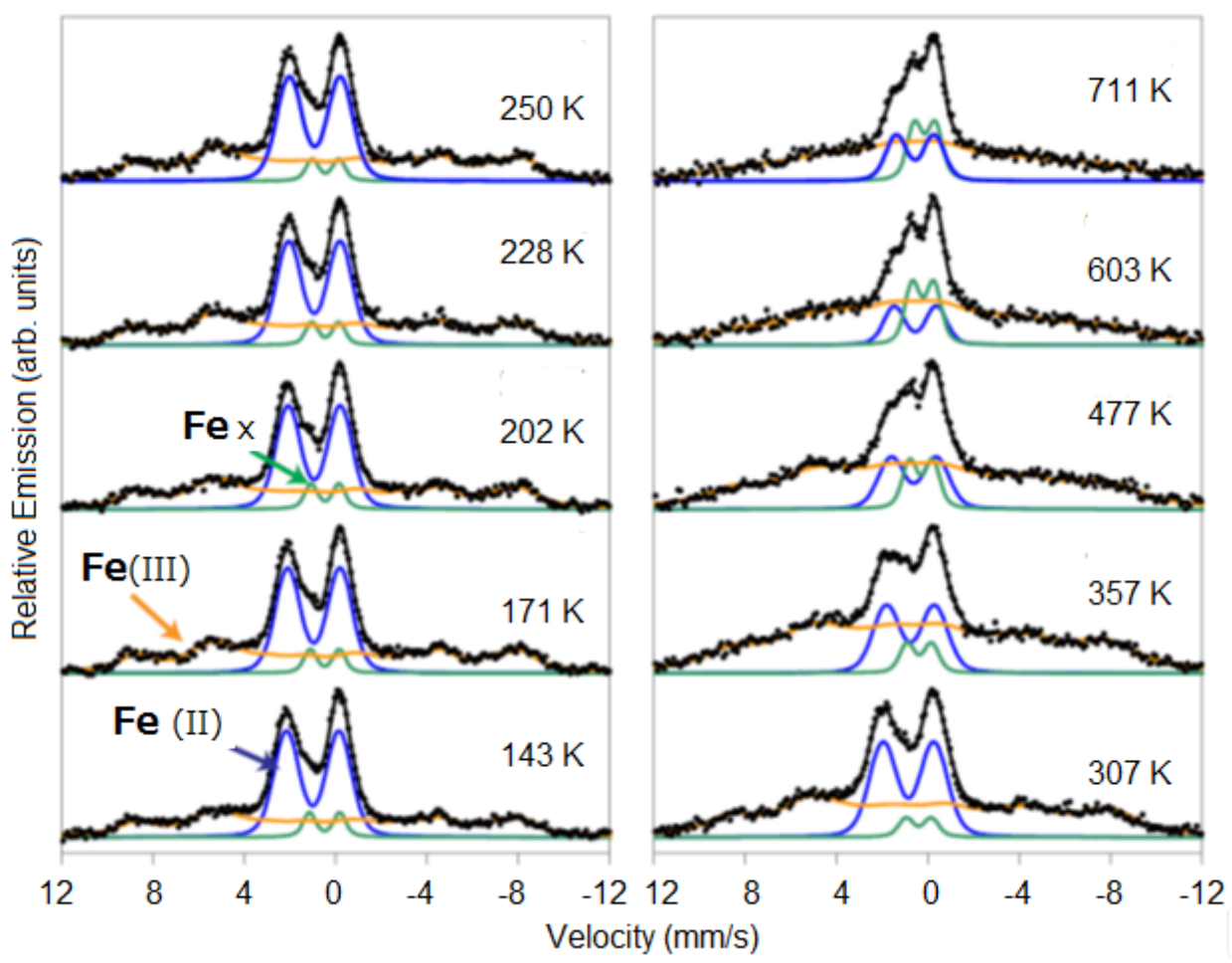

Figure 13. ${ }^{57} \mathrm{Fe}$ emission Mössbauer spectra of dilute (ca. $\left.5 \times 10^{-4} \%\right){ }^{57} \mathrm{Mn}$ ion implanted $\mathrm{SnO}_{2}$ film in ISOLDE. ${ }^{26]}$

with ${ }^{57} \mathrm{Fe}$. The transformation process of implanted Fe species can be suggested from the peak intensity ratios of the decomposed spectral components.

The paramagnetic $\mathrm{Fe}^{2+}$ species, which are located in amorphous phases produced locally by $40 \mathrm{keV}$ ion implantation, are oxidized into $\mathrm{Fe}^{3+}$ at the temperatures higher than $330 \mathrm{~K}$. The oxidized $\mathrm{Fe}^{3+}$ species, which may be located in the crystalline phase at the higher temperatures, contribute to the paramagnetic relaxation peaks in the emission Mössbauer spectra. A part of the oxidized $\mathrm{Fe}^{3+}$

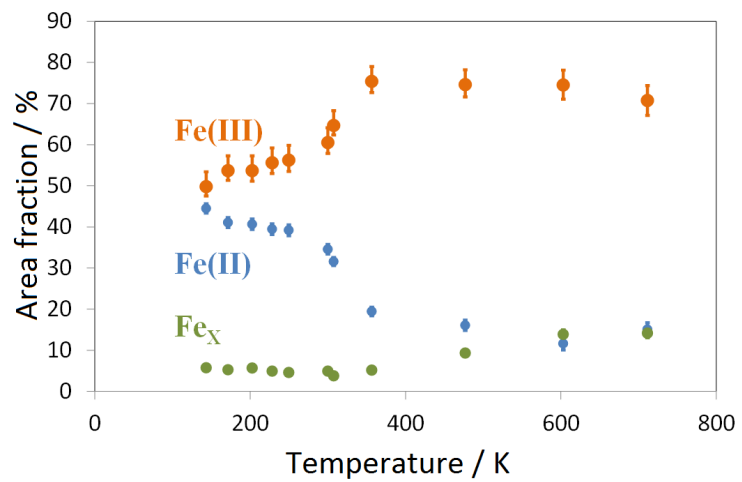

Figure 14. Temperature dependence of area fraction of components: $\mathrm{Fe}_{\mathrm{x}}$ : interstitial $\mathrm{Fe}^{3+}, \mathrm{Fe}(\mathrm{II}): \mathrm{Fe}^{2+}$, and $\mathrm{Fe}(\mathrm{III})$ : paramagnetic relaxation $\mathrm{Fe}^{3+} \cdot{ }^{[26]}$ species, which are recoiled and located at the interstitial sites, contribute to the sharp doublet of $\mathrm{Fe}^{3+}\left(\mathrm{Fe}_{x}\right.$ in Figures 13 and 14). The another possible explanation is that $\mathrm{Fe}^{3+}$ atoms that are relocated from a substitutional site due to the recoil in the $\beta$-decay in an environment characterized by a high concentration of vacancy defects can more easily be incorporated into substitutional sites. Consequently, as the defects density reduces at elevated temperatures, the probability for observing interstitial $\mathrm{Fe}^{3+}$ increases. ${ }^{[26]}$

\section{MAGNETIC MOMENTS AND OXYGEN VACANCIES OF Fe DOPED $\mathrm{SnO}_{2}$ BY $A B$ INITIO CALCULATION ${ }^{[27]}$}

The experimental Mössbauer parameters of Fe doped $\mathrm{SnO}_{2}$ were summarized into four groups: $\mathrm{Fe}^{3+}(11), \mathrm{Fe}^{3+}(\mathrm{I} 2), \mathrm{Fe}^{3+}$ (I3) and $\mathrm{Fe}^{2+}(14)$ (Figure 15). Groups $\mathrm{I} 1$ and $\mathrm{I} 2$ are often observed in Mössbauer spectra measured. Groups 13 and 14 are in Mössbauer spectra obtained by ion implantation and ball milling. Two main interactions ( 11 and I2) observed in Mössbauer spectra can be associated to Fe-ions substituted at the $\mathrm{Sn}$ sites with oxygen coordination number smaller than six. That is, $\mathrm{Fe}^{3+}$ doping into $\mathrm{SnO}_{2}$ induces oxygen vacancy. The parameters are confirmed by $a b$ initio calculations for configurations of substituted $\mathrm{Fe}$ and oxygen vacancy (VO) as shown in Figures 16 and 17. The third interaction (I3) is characterized by a low IS (in the order of 


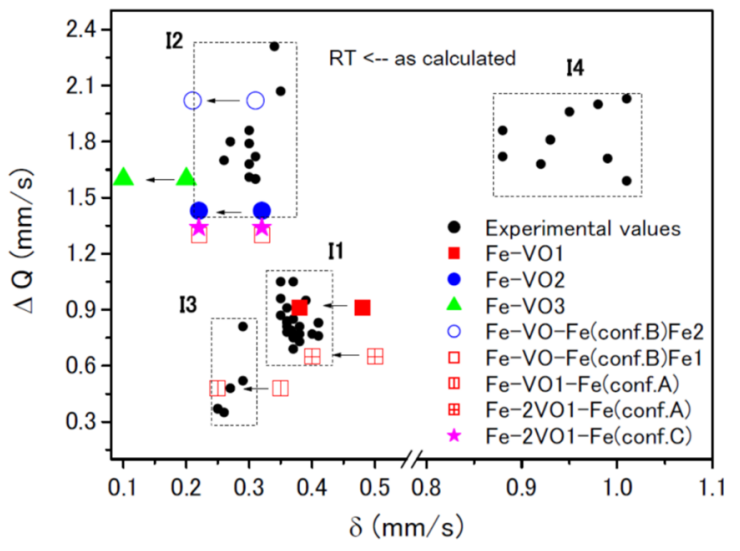

Figure 15. Isomer shift $(\delta)$ and quadrupole splitting $(\Delta Q)$ of experimental data and $a b$ initio calculation: configurations of occupied Fe ions and oxygen vacancy (VO). The calculated values at $R T$ shifted by ca. $-0.1 \mathrm{~mm} \mathrm{~s}^{-1}$ due to secondary Doppler shifts (depending on the temperature) from as calculated ones are added in the original figure. ${ }^{[27]}$

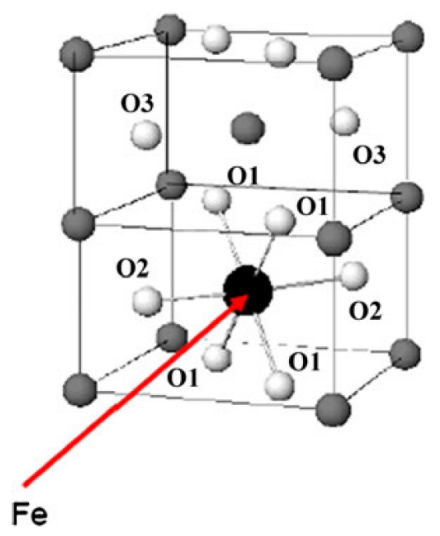

Figure 16. Configuration of one substituted Fe at Sn site and one oxygen vacancy (VO) (distance between Fe and VO: Fe$\mathrm{VO} 1<\mathrm{Fe}-\mathrm{VO} 2<\mathrm{Fe}-\mathrm{VO} 3$ ) $\mathrm{O} 1$ and $\mathrm{O} 2$ correspond to oxygen atoms in the first shell of oxygen neighbors of $\mathrm{Fe}$, and $\mathrm{O} 3$ is an oxygen in the second shell of Fe-oxygen neighbors. ${ }^{[27]}$

$0.20 \mathrm{~mm} \mathrm{~s}^{-1}\left(0.10 \mathrm{~mm} \mathrm{~s}^{-1}\right.$ at $\left.R T\right)$. Fe atoms replacing $\mathrm{Sn}$ with oxygen vacancy are far away from the first shell of oxygen neighbours. It is not often observed in experimental data.

In the case of one Fe substituted at $\mathrm{Sn}$ site in $\mathrm{SnO}_{2}$ lattice and one oxygen vacancy, average Fe-ONN bondlength is in good agreement with the distances obtained from the EXAFS analysis $(0.198 \mathrm{~nm})$. It suggests that oxygen vacancies near the doped $\mathrm{Fe}$ are more stable than those near $\mathrm{Sn}$ in the lattice. Doping Fe ions lowers the formation energy of oxygen vacancies. The presence of an oxygen vacancy close to the Fe ions increases the split between iron $3 d$ levels resulting in a higher magnetic moment of the Fe atoms. ${ }^{[27]}$

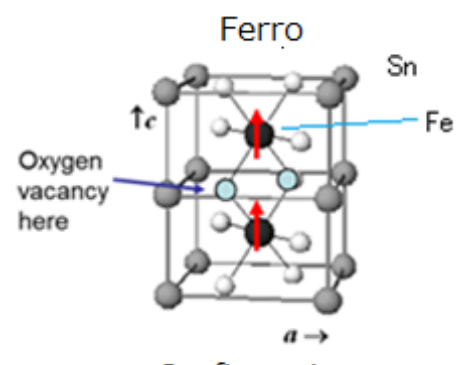

Configuration a

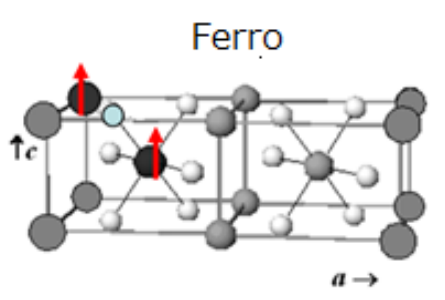

Configuration $b$

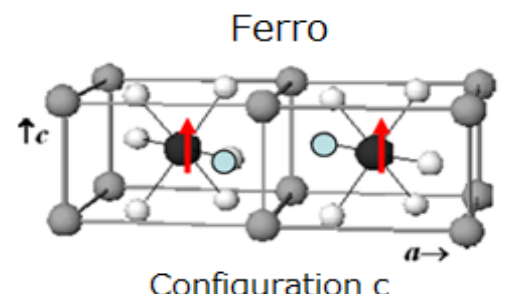

Figure 17. Configurations of $\mathrm{Sn}, \mathrm{Fe}, \mathrm{O}$ and Oxygen vacancy (VO) in rutile structure of $\mathrm{SnO}_{2}$ doped with Fe. Part of the $2 \times 2 \times 2$ super cell (SC) showing the different distribution of the Fe atoms (black balls) substituted at $\mathrm{Sn}$ sites. Configuration a: Fe-2VO-Fe; configuration b: Fe-VO-Fe; and configuration c: Fe-2VO-Fe. ${ }^{[27]}$

The cases of two irons sharing oxygen vacancies are shown to search the preferential magnetic alignment as shown in Figure 17. ${ }^{[27]}$ The lowest energy state for all configurations is the ferromagnetic one and in this case Fermi level falls onto minority $3 \mathrm{~d}$ level. The doping with transition iron atoms reduces the formation energy of oxygen vacancy. Fe doped $\mathrm{SnO}_{2}$ systems will have more vacancies than the undoped ones. Oxygen vacancies enhance the magnetic moment of doped Fe impurities in supercell as listed in Table 1.

Oxygen vacancies prefer to be in the $\mathrm{Fe}-\mathrm{O}-\mathrm{Fe}$ path favoring the ferromagnetic coupling between Fe dopants. Small quantities of oxygen vacancies are fundamental for stabilizing local ferromagnetism in the form of bound magnetic polarons (BMPs). Two Fe ions sharing an oxygen vacancy are coupled ferromagnetically, forming a bound magnetic polaron (BMP), and that two neighbor BMPs are aligned antiparallel to each other although the formation energy is so very small as shown Figure $18 .{ }^{[27]}$ 
Table 1. Calculated hyperfine parameters $\delta$ and $|\Delta Q|$; magnetic moment in the super cell $\left(\mu^{\mathrm{SC}}\right)$ for the different vacancy positions studied. S: Substitutional and I: Interstitial.[27] NV, 1VO, and 2 VO indicate the cases without oxygen vacancies or one or two oxygen vacancies in the super cell (SC). In the case of Configuration b with one oxygen vacancy, the results for the $\delta$, the $|\Delta Q|$, and $\mu^{\mathrm{imp}}$ refers to each inequivalent Fe site of the structure.

\begin{tabular}{|c|c|c|c|c|c|c|c|c|}
\hline & Configulation & $\begin{array}{r}O \\
\text { Vaca }\end{array}$ & $\begin{array}{l}\text { ygen } \\
\text { cy (VO) }\end{array}$ & $\begin{array}{c}\delta / \mathrm{mm} \mathrm{s}^{-1} \\
\delta(\text { at } R T)\end{array}$ & $\begin{array}{l}|\Delta Q| / \\
\mathrm{mm} \mathrm{s}^{-1}\end{array}$ & $\mu^{\mathrm{imp}} / \mu_{\mathrm{B}}$ & $\mu^{\mathrm{SC}} / \mu_{\mathrm{B}}$ & $\begin{array}{c}\text { Magnetic Order (formation } \\
\text { energy: } \Delta E / \mathrm{eV} \text { ) }\end{array}$ \\
\hline \multirow{7}{*}{$2 \mathrm{Fe}(\mathrm{S})$} & \multirow{3}{*}{ a } & \multicolumn{2}{|c|}{ NV. } & $0.15(0.05)$ & 1.26 & \pm 1.80 & 0.0 & $\operatorname{AF}(-0.136)$ \\
\hline & & \multirow{2}{*}{\multicolumn{2}{|c|}{$\begin{array}{l}\mathrm{Fe}-1 \mathrm{VO} \\
\mathrm{Fe}-2 \mathrm{VO}\end{array}$}} & $0.38(0.28)$ & 0.65 & \pm 3.52 & 0.0 & $\operatorname{AF}(-0.095)$ \\
\hline & & & & $0.50(0.40)$ & 0.65 & 3.40 & 8.5 & $\mathrm{FM}(0.082)$ \\
\hline & \multirow[b]{2}{*}{ b } & \multicolumn{2}{|c|}{ NV } & $0.14(0.04)$ & 2.50 & 1.63 & 0.0 & AF $(-0.068)$ \\
\hline & & \multicolumn{2}{|c|}{ Fe-1 Vo } & $\begin{array}{c}0.32(0.22) / \\
0.31(0.21)\end{array}$ & $1.30 / 2.02$ & $2.43 / 2.48$ & 6.0 & FM (0.054) \\
\hline & \multirow{3}{*}{ c } & \multirow{2}{*}{\multicolumn{2}{|c|}{$\begin{array}{c}\mathrm{NV} \\
\mathrm{Fe}-2 \mathrm{VO}\end{array}$}} & $0.12(0.02)$ & 2.24 & 1.63 & 4.0 & FM (0.013) \\
\hline & & & & $0.32(0.22)$ & 1.34 & 2.38 & 6.0 & FM (0.027) \\
\hline \multirow{7}{*}{$\begin{array}{l}1 \mathrm{Fe}(\mathrm{S}) \\
1 \mathrm{Fe}(\mathrm{I})\end{array}$} & & & । & $0.50(0.40)$ & $0.50(0.40)$ & 1.43 & 0.36 & \\
\hline & \multirow{3}{*}{ a } & NV & S & $0.45(0.33)$ & $0.45(0.33)$ & 0.73 & -0.66 & -0.76 \\
\hline & & $\mathrm{Fe}-$ & I & $0.40(0.30)$ & 0.88 & -0.17 & \multirow{2}{*}{-3.77} & \multirow{2}{*}{ AF } \\
\hline & & VO & S & $0.52(0.42)$ & 0.64 & 3.45 & & \\
\hline & \multirow{3}{*}{ b } & NV & 1 & $0.65(0.55)$ & 0.72 & -1.69 & \multirow{2}{*}{-2.56} & \multirow{2}{*}{$\mathrm{AF}$} \\
\hline & & TNV & S & $0.63(0.53)$ & 0.42 & -3.63 & & \\
\hline & & $\begin{array}{l}\mathrm{Fe}- \\
\mathrm{VO}\end{array}$ & $\begin{array}{l}1 \\
S\end{array}$ & $\begin{array}{l}0.46(0.36) \\
0.60(0.50)\end{array}$ & $\begin{array}{l}1.12 \\
1.95\end{array}$ & $\begin{array}{c}0.95 \\
-2.56\end{array}$ & -2.00 & $\mathrm{AF}$ \\
\hline \multirow{4}{*}{$1 \mathrm{Fe}(\mathrm{S})$} & & NV & s & $0.13(0.03)$ & 2.43 & 1.63 & 2.00 & Av. bond length $<d>0.1913 \mathrm{~nm}$ \\
\hline & & $\begin{array}{l}\mathrm{Fe}- \\
\mathrm{VO1}\end{array}$ & S & $0.48(0.38)$ & 0.91 & 3.62 & 4.54 & $0.1967 \mathrm{~nm}$ \\
\hline & & $\begin{array}{l}\mathrm{Fe}- \\
\mathrm{VO} 2\end{array}$ & S & $0.32(0.22)$ & 1.43 & 2.42 & 2.99 & $0.1912 \mathrm{~nm}$ \\
\hline & & $\begin{array}{l}\mathrm{Fe}- \\
\mathrm{VO} 3\end{array}$ & S & $0.20(0.10)$ & 1.60 & 1.44 & 1.88 & $0.1918 \mathrm{~nm}$ \\
\hline
\end{tabular}

In the case of ${ }^{57} \mathrm{Mn}$ implanted $\mathrm{SnO}_{2}$ films, the Mössbauer spectra present two doublets, one with IS = $0.48 \mathrm{~mm} \mathrm{~s}^{-1}$ and $\Delta Q=0.91 \mathrm{~mm} \mathrm{~s}^{-1}$ and the other with IS $=$ $0.89 \mathrm{~mm} \mathrm{~s}^{-1}$ and $\Delta Q=2.20 \mathrm{~mm} \mathrm{~s}^{-1}$. Comparing with calculated values for one interstitial Fe atom, there is poor agreement between experimental and calculated results, but there is good agreement with the situation where the interstitial $\mathrm{Fe}$ has a substitutional iron near neighbor (configuration b with one oxygen vacancy in Table 1).

\section{Long Range Magnetic Ordering}

From the calculation of the configurations as shown Figure 18 , it is found that the configuration with smaller energy is the antiferromagnetic one. Then, ferromagnetic interaction is only in short range while long range interaction is antiferromagnetic. The energy difference between both alignments is $\Delta E=-0.05 \mathrm{eV}$; that is, the antiferromagnetic alignment is a little favored. Thus, although an increase in iron concentration would favor a neighboring situation with the increase in the number of BMP, the antiferromagnetic BMP alignment would reduce the magnetization, which is in very good agreement with the experimental results. It is to note in experimental results that the $\mathrm{Sb}^{5+}$ ions codoping of $\mathrm{SnO}_{2}\left(\mathrm{Fe}^{3+}\right)$ increases the saturation magnetization. The electron doping was simulated in two different ways: adding one electron to the 108-atom supercell (SC) or replacing
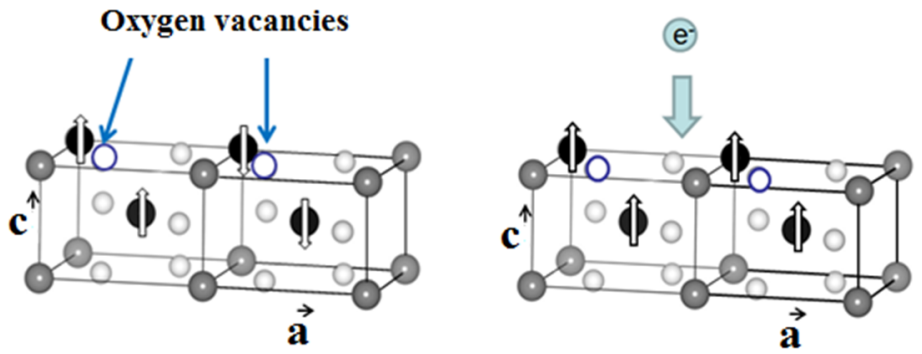

Figure 18. Part of the $3 \times 2 \times 3$ SC showing the bound magnetic polaron model for (a) antiferromagnetic alignment and (b) ferromagnetic alignment among BMPs. Open circles indicates the position of the oxygen vacancies. ${ }^{[27]}$ 
one indigenous $\mathrm{Sn}$ atom by a donor impurity such as $\mathrm{Sb}^{5+}$. Both approaches suggest that the ferromagnetic coupling between $\mathrm{BMP}$ is the most stable configuration with $\Delta E=$ $E_{\text {anti }}-E_{\text {ferro }}$ on the order of $+0.3 \mathrm{eV}$. This result shows that electron doping plays a fundamental role in mediating the nonlocal magnetic coupling between two BMP. From the experimental results it was considered that the overall magnetic properties of TM-doped $\mathrm{SnO}_{2}$ are a statistical average of different defect configurations corresponding to a real disordered system. ${ }^{[27]}$

\section{SUMMARY}

The intrinsic DMS and extrinsic DMS have been experimentally obtained for dilute iron doped $\mathrm{SnO}_{2}$. Concerning intrinsic DMS, oxygen vacancies are fundamental for the ferromagnetic response of Fe-doped $\mathrm{SnO}_{2}$. The ab initio calculations show the possibility that two Fe ions sharing an oxygen vacancy are coupled ferromagnetically, forming a bound magnetic polaron (BMP), and that two neighbor BMPs are aligned antiparallel to each other. However, the formation energy for the antiferromagnetic alignment is so small that electron doping by $\mathrm{Sb}^{5+}$ can play a fundamental role of mediating the magnetic coupling between the BMP inducing ferromagnetic alignment between the BMPs. ${ }^{[27]}$

A codoping two transition metals in $\mathrm{SnO}_{2}$ also enhances the dilute ferromagnetism together with inducing the oxygen vacancies, and the $a b$ initio calculation for these configurations would be studied in near future.

As the new composite material, the nano magnetic material precipitated in semiconductors, such as $\mathrm{SnO}_{2}$ film obtained by Fe ion implantation, would be useful from the view point of practical application.

Acknowledgment. This paper presents a review article based on the author talk about oxygen defects and diluted magnetism of $\mathrm{SnO}_{2}$ doped with $\mathrm{Fe}$ which was presented at the Mediterranean Conference on the Applications of Mössbauer Effect, MECAME 2015, Zadar, Croatia. MECAME 2015 was organized in honour of Dr. Svetozar Musić on the occasion of his $70^{\text {th }}$ birthday and to celebrate his life-long scientific contribution, particularly for his introduction of Mössbauer spectroscopy as a research technique in Croatia. Dr. Svetozar Musić has worked in the field of metal oxides chemistry for more than four decades and especially in the iron oxide chemistry. Author of this article had worked with him on the Mössbauer analysis of iron oxide nano-powders. As the result of this collaboration the common papers were published and are listed in the references. ${ }^{28}$ These nanoscale oxide materials are expected to be used for producing new spintronic materials by embedding them into semiconductors. Author would like to express many thanks to Dr. S. Music for giving him a chance for this research field.
Prof. Cesar Barrero from the Universidad de Antioquia have also contributed a lot to the study of DMS research since he visited the University of Tokyo, and his research group continued working in this field. Dr. H. P. Gunnlaugsson, Dr. K. Johnston, Prof. G. Langouche and the other members in ISOLDE group have engaged in emission Mössbauer spectrometry of super dilute magnetic ions doped oxide materials. This experimental research is important for development of RT- DMS materials.

One of the aims of this review paper is to show the clear relationship between magnetic moments and configurations of substituted $\mathrm{Fe}$ atoms and oxygen vacancies by ab initio calculation of Fe-doped $\mathrm{SnO}_{2}$ system. The experimental works have been done at the School of Engineering, the University of Tokyo, where author has been working for past 35 years. The ab initio calculations were supported by Dr. Azucena Mudarra Navarro, Prof. Claudia E. Rodriguez Torres, Prof. Leo A. Erico and so on from the University of La Plata.

There are a lot of coworkers who contributed to this research as shown in the following references. In addition to above mentioned coworkers the author would like to express special thanks to all coworkers named in the cited references, and to Prof. Akira Fujishima, Tokyo University of Science, for supporting author's study. Finally, author expresses thanks to Dr. Mira Ristić, the organizer of the MECAME 2015 for carefully reading of this manuscript.

\section{REFERENCES}

[1] T. Dietl, Semicond. Sci. Tech. 2002, 17, 377.

[2] Y. Matsumoto, M. Murakami, T. Shono, T. Hasegawa, T. Fukumura, M. Kawasaki, P. Ahmet, T. Chikyow, S. Koshihara, H. Koinuma, Science 2001, 291, 854.

[3] (a) T. Dietl, H. Ohno, F. Matsukura, J. Cibert, D. Ferrand, Science 2000, 287, 1019; (b) S. J. Pearton, C. R. Abernathy, G. T. Thaler, R. Frazier, F. Ren, A. F. Hebard, Y. D. Park, D. P. Norton, W. Tang, M. Stavola, J. M. Zavada, R. G. Wilson, Physica B 2003, 340-342 39-47.

[4] S. B. Ogale, R. J. Choudhary, J. P. Buban, S. E. Lofland, S. R. Shinde, S. N. Kale, V. N. Kulkarni, J. Higgins, C. Lanci, R. Simpson, N. D. Browning, S. D. Sharma, H. D. Drew, R. L. Greene, T. Venkatesan, Phys. Rev. Lett. 2003, 91, 077205 (4p).

[5] K. Nomura, Y. Ujihira, H. Shiozawa, T. Takada, H. Reuther, E. Richter, J. Mater. Sci. Mater. Electron. 1997, 8, 301.

[6] K. Nomura, Radioisotopes 2013, 62, 857.

[7] J. M. D. Coey, M. Venkatesan, C. B. Fitzgerald, Nature Mater. 2005, 4, 173.

[8] J. M. D. Coey, S. A. Chambers, MRS Bulletin 2008, 33, 1053. 
[9] K. Nomura, T. Okubo, M. Nakazawa, Spectrochim. Acta B 2004, 59, 1259.

[10] A. I. Rykov, K. Nomura, J. Sakuma, C. Barrero, Y. Yoda, T. Mitsui, Phys. Rev. B 2008, 77, 014302-1014302-8.

[11] K. Nomura, K. Inaba, S. lio, T. Hitosugi, T. Hasegawa, Y. Hirose, Z. Hommonay, Hyperfine Interact. 2006, $168,1065$.

[12] Z. Homonnay, K. Nomura, E. Kuzmann, A. Vértes, Y. Hirose, T. Hasegawa, Hyperfine Interact. 2008, 184, 69.

[13] K. Nomura, C. A. Barrero, J. Sakuma, M. Takeda, Phys. Rev. B 2007, 75, 184411 (13p).

[14] K. Nomura, C. A. Barrero, K. Kuwano, Y. Yamada, T. Saito, E. Kuzmann, Hyperfine Interact. 2009, 191, 25.

[15] K. Nomura, E. Kuzmann, C. A. Barrero, S. Stichleutner, Z. Homonnay, Hyperfine Interact. 2008, 184, 57.

[16] K. Nomura, A. Rykov, Z. Nemeth, Y. Yoda, Hyperfine Interact. 2012, 205,129.

[17] K. Nomura, J. Okabayashi, K. Okamura, Y. Yamada, J. Appl. Phys. 2011, 110, 083901 (4p).

[18] S. Kono, K. Nomura, Y. Yamada, J. Okabayashi, Hyperfine Interact. 2012, 205, 105.

[19] J. Okabayashi, K. Nomura, S. Kono, Y. Yamada, Jpn. J. Appl. Phys. 2012, 51, 023003 (4p).

[20] J. Okayabashi, K. Nomura, S. Kono, Y. Yamada, J. Appl. Phys. 2012, 112, 073917 (5p).

[21] J. Okabayashi, S. Kono, Y. Yamada, K. Nomura, Hyperfine Interact. 2013, 217, 99.

[22] K. Nomura, H. Reuther, Hyperfine Interact. 2009, $191,159$.
[23] K. Nomura, Z. Németh, H. Reuther, J. Phys. Conf. Ser. 2010, 217, $012118(4 p)$.

[24] K. Nomura, S. lio, Y. Hirose, H. Reuther, A. Nakanishi, Hyperfine Interact. 2013, 217, 37.

[25] K. Nomura, S. lio, Y. Hirose, Z. Németh, K. Yamamoto, H. Reuther, J. Nucl. Radiochem. Sci. 2010, 11, 1.

[26] H. P. Gunnlaugsson, K. Nomura, T. E. Mølholt, S. Shayestehaminzadeh, K. Johnston, R. Mantovan, H. Masenda, M. Ncube, K. Bharuth-Ram, H. Gislason, G. Langouche, D. Naidoo, S. Ólafsson, G. Weyer, the ISOLDE Collaboration, Hyperfine Interact. 2014, 226, 389.

[27] A. M. Mudarra Navarro, C. E. Rodríguez Torres, A. F. Cabrera, M. Weissmann, K. Nomura, L. A. Errico, J. Phys. Chem. C 2015, 119, 5596.

[28] Dr. Svetozar Musić paper list, co-worked with K. Nomura: (a) A. Šarić, K. Nomura, S. Popović, N. Ljubešić, S. Musić, Mater. Chem. Phys. 1998, 52, 214; (b) A. Šarić, S. Musić, K. Nomura, S. Popović, Mater. Sci. Eng. B 1998, 56, 43; (c) A. Šarić, S. Musić. K. Nomura, S. Popović, Croat. Chem. Acta 1998, 71, 1019; (d) A. Šarić, S. Musić. K. Nomura, S. Popović, J. Mol. Struct. 1999, 480-481, 633; (e) G. Štefanić, S. Musić, S. Popović, K. Nomura, J. Mol. Struct. 1999, 480-481, 627; (f) S. Musić. A. Šarić, K. Nomura, S. Popović, ACH - Models Chem. 1999, 136, 457; (g) S. Musić, A. Šarić, S. Popović, K. Nomura, T. Sawada, Croat. Chem. Acta 2000, 73, 542; (h) G. Štefanić, B. Gržeta, K. Nomura, R. Trojko, S. Musić, J. Alloys Compd. 2001, 327, 151. 